\title{
LABSOL E COROA IMPERIAL: A FORMAÇÃO DO PATRIMÔNIO CULTURAL NA PRODUÇÃO DE FANTASIAS DE ALA PARA O CARNAVAL 2016
}

\author{
Michael Garcia da Rocha \\ UNESP - Universidade Estadual Paulista Júlio de Mesquita Filho \\ garciar.michael@gmail.com \\ Claudio Roberto y Goya \\ UNESP - Universidade Estadual Paulista Júlio de Mesquita Filho \\ goyaclaudio@hotmail.com \\ Maiara Marinho \\ UNESP - Universidade Estadual Paulista Júlio de Mesquita Filho \\ mai_marinho@hotmail.com \\ Cassio Rodrigues Lima \\ UNESP - Universidade Estadual Júlio de Mesquita Filho \\ cass.rodrigues@hotmail.com
}

Resumo: Neste artigo será relatado os resultados obtidos pelo Labsol, Laboratório de Design Solidário, da UNESP - Universidade Estadual Paulista Júlio de Mesquita Filho, Campus Bauru, na criação de fantasias de ala para o Grêmio Escola de Samba Coroa Imperial da Grande Cidade no carnaval 2016, levando em consideração os pilares do Projeto: ecodesign, sustentabilidade e economia solidária. Não esquecendo da experiência de seus integrantes em levar o conhecimento da universidade para a comunidade, as considerações da relação comunidade-extensão e como essa fora importante para o acréscimo de conhecimento tanto para o projeto quanto para a comunidade. Além de uma descrição de materiais e métodos utilizados na produção destas fantasias.

Palavras-chave: carnaval, fantasia, patrimônio cultural, ecodesign

\begin{abstract}
This article will report the results of Labsol - Laboratory of Solidarity Design, on UNESP - State of São Paulo University Júlio de Mesquita Filho, Campus Bauru, on creating wing costumes for Grêmio Escola de Samba Coroa Imperial da Grande Cidade in the biggest popular festival of Brazil, Carnaval 2016, considering our design pillars: ecodesign, sustainability and solidarity economy and the experience of our members to teach the university knowledge to local community. The comments of the relationship community-university and how this was important to increase knowledge to both sides of the project. Besides a description of materials and methods udes in producing these costumes.
\end{abstract}

Key Words: carnaval, costume, cultural heritage, ecodesign 


\section{INTRODUÇÃO}

O Laboratório de Design Solidário, projeto de extensão universitária do curso de Design, Faculdade de Arquitetura, Artes e Comunicação (FAAC), da Universidade Estadual Paulista "Júlio de Mesquita Filho", campus de Bauru, pauta suas ações no desenvolvimento do artesanato com comunidades brasileiras que demonstrem a demanda por aprimorar suas criações quanto ao design e suas possibilidades. Por meio do design social, voltado para os problemas sociais, como é o caso de comunidades que se unem para gerar renda, mas encontram dificuldades, o projeto pode contribuir para melhorar a inserção no mercado e principalmente despertar o potencial de expressar a identidade, seja ela individual ou coletiva e a cultura das localidades onde o artesanato é produzido.

Desde 2007 o projeto vem atendendo comunidades e em 2013 surgiu o convite, por parte de um outro projeto da UNESP, o NEOCRIATIVA, para desenvolver fantasias e alegorias para uma escola de samba do município de Bauru, o Grêmio Recreativo Escola de Samba Coroa Imperial da Grande Cidade, que apresentava problemas de ordem financeira. A ideia inicial era trabalhar com materiais recicláveis. Entretanto, após o diagnóstico da situação da escola descobriu-se um grande número de fantasias de carnavais passados que poderiam ter seus materiais reaproveitados, aumentando assim seu ciclo de vida útil.

A parceria teve grandes resultados, na qualidade das fantasias em vários aspectos, nos resultados da colocação da escola no carnaval bauruense, mas principalmente, na reunião da comunidade no entorno da escola, proporcionando um claro resgate da auto-estima e do sentimento de pertencimento.

Por três anos consecutivos, o LABSOL desenvolveu com a comunidade todas as fantasias e alegorias dos carros alegóricos, aprimorando técnicas e aprendendo como ensinar aos voluntários o processo de produção seriada das fantasias.

No ano de 2016 o enredo escolhido foi América: Mestiça, Mãe, Terra e procurou retratar de forma resumida, em função dos recursos limitados, o que há de mais representativo na história e na cultura da América Latina, desde sua origem quando era habitada pelos povos pré-colombianos, passando por grandes símbolos, até o os "chamados caudilhos de la pelota", nome dado a um carro alegórico que abordou um pouco da história dos grandes líderes de todos os tempos, como Simón Bolívar e Fidel Castro; e o famigerado apreço pelo futebol, marcante nos países: Uruguai, Argentina e Brasil.

Este artigo pretende esmiuçar parte do resultado da parceria deste ano, por meio da descrição das fantasias de ala, relatando a inspiração para sua criação de acordo com o enredo escolhido, seu processo de criação, bem como das contingências na relação com a comunidade da Coroa Imperial. O percurso será traçado de forma a descrever os procedimentos metodológicos adotados pelo Labsol nesse importante e inovador trabalho da extensão universitária a serviço da preservação desse patrimônio cultural brasileiro - o carnaval.

\section{DESENVOLVIMENTO}

\subsection{Labsol}

Apresentação do problema de estudo. Explicitação da metodologia e ou do Referencial Teórico. 
O LabSol (Laboratório de Design Solidário), é um projeto de Extensão Universitária do Departamento de Design da Faculdade de Arquitetura, Artes e Comunicação da Universidade Estadual Paulista, UNESP Campus de Bauru, que, desde 2007, visa atender comunidades de baixa renda que tem no artesanato sua forma básica de subsistência. A proposta central é a promoção de ações conjuntas entre o design e o patrimônio cultural do artesanato, preocupando-se com a qualificação do produto artesanal e sua inserção no mercado a partir do tripé conceitual: Sustentabilidade (MANZINI, 2002), a Economia Solidária (SINGER, 2002) e o Ecodesign (BREZET, 1997), atendendo, numa relação dialógica (FREIRE, 1987) grupos de artesãos e comunidades, objetivando a geração de trabalho e renda, a fim de promover a autossustentabilidade de grupos produtores de artefatos.

O projeto é composto atualmente por alunos dos cursos de Design: voluntários, bolsistas do CNPq em iniciação científica, da PROEx Unesp, e do Programa de Permanência Estudantil da Unesp. E tem desenvolvido uma grande quantidade de conhecimentos novos, tanto na criação de novos produtos, quanto no desenvolvimento de métodos e técnicas em Design Social.

O Labsol envolve os três aspectos da Universidade, para além da extensão universitária, contribuindo para a formação da cidadania em nossos alunos, desvinculando-se do capital internacional e produção em massa, e oferecendo apoio às comunidades, age também como laboratório didático e de pesquisa, tendo apresentado nos últimos anos dezenas de trabalhos científicos em congressos, ministrado oficinas de divulgação e realizado workshops, demonstrando desse modo a indissociabilidade do tripé ensino-pesquisa-extensão.

\subsection{Labsol + Coroa Imperial}

As subseções são numeradas em algarismos arábicos.

O Primeiro contato entre o Labsol e a Coroa Imperial, se deu através do grupo de estudos Neocriativa, da UNESP de Bauru que tem o intuito de estudar a Economia Criativa e os arranjos produtivos culturais da cidade, coordenado pelo professor Juarez Xavier, da UNESP, que reconheceu que o Labsol, possuía condições de contribuir com o carnaval bauruense e a Coroa Imperial. Dessa feita, junto com a professora Ana Beatriz de Andrade do Departamento de Design da FAAC, convidaram o professor coordenador do Labsol, Cláudio Roberto Y Goya, para conhecer os dirigentes do Grêmio Escola de Samba Coroa Imperial da Grande Cidade. Já na primeira reunião foi possível perceber que escola passava por sérias dificuldades, pela ausência de carnavalesco e pelos poucos recursos financeiros de que dispunha para realizar o carnaval do então ano de 2014.

Assim começou o contato do Labsol com a Coroa Imperial, que perduraria três anos. A princípio pensava-se em trabalhar com materiais já tradicionalmente recicláveis, mas a visita ao depósito da escola de samba fez com que se abandonasse a premissa de projeto, pois nele existia uma enormidade de materiais usados: fantasias, saias de carros, e mesmo material novo não utilizado pelos carnavalescos anteriores. Assim as o Labsol se propôs a trabalhar a partir daquele resíduo, desenvolvendo o projeto e construindo as peças piloto das fantasias.

Ao trabalhar junto a Comunidade da Escola de Samba pode-se observar muitos fatos que fazem refletir sobre a relação entre o Design (erudito) e a cultura popular. A 
comunidade perdeu todas as fichas técnicas e grande parte dos moldes, entregues junto as peças piloto. Desta aparente displicência percebeu-se que para eles, a ideia do projeto não é transmitida a partir do registro gráfico, assim os moldes e fichas técnicas não Ihes apresentava significado, assim como preferiam recortar as peças individualmente (com grande desperdício de material e de tempo) e executar as fantasias uma a uma. Verificou-se que questões como o processo de produção em série eram bastante estranhas a essa comunidade.

Somente ao se entender que todo o processo de construção da cultura popular se faz por meio da tradição oral, e passar a demonstrar como eram feitas as fantasias, executando peças junto com as pessoas que executariam realmente as fantasias, demonstrando que ao se dobrar os materiais, ou colocá-los em camadas cortando diversas peças de uma só vez se ganhava tempo, mostrando como era importante a ficha técnica na quantificação das compras de material, e que separando a construção das fantasias em etapas e é que o processo de apreensão do projeto se deu. Sendo esse o método como o Labsol atuou em toda sua estada com a comunidade.

\subsection{Enredo carnaval 2016}

Levando em consideração que a criatividade geralmente resulta de associações, combinações, ou visão sob um novo ângulo, de ideias existentes (BAXTER; Mike, 2011). O novo enredo foi escolhido fazendo uso da técnica "brainstorm". Dessa reunião fizeram parte membros da Escola de Samba, entre comunidade e diretoria, e membros do projeto LabSol, resultando no tema que versa sobre a América Latina, emergindo da noção de que o Brasil acaba se isolando do restante do continente, esquecendo-se de olhar mais para os nossos vizinhos de continente. A princípio o enredo seria "Soy loco por ti América", entretanto o pouco número de alas, apenas 10 pela falta de recursos, foi substituído por "América: Mestiça. Mãe. Terra." e procuraria abranger os povos que construíram este continente e as suas diversas regiões etno-geográficas.

\subsection{Produção de fantasias de ala}

Após a escolha do enredo da Coroa Imperial - América: Mestiça. Mãe. Terra. Proveniente do trabalho dos dirigentes da Escola de Samba, do Orientador do Projeto e de alguns integrantes do Labsol, fora definido as alas e seus temas, assim como carros alegóricos.

Definido isso, os integrantes do Labsol começaram uma árdua pesquisa icnográfica de elementos que poderiam compor as fantasias e as alegorias das 10 (dez) alas definidas até então. Com isso foram escolhidas as paletas de cores que fariam parte de cada ala, levando em conta a identidade de cada tema, e preocupando-se com a ligação entre elas, a fim de manter uma ligação entre todas as alas.

Começou-se então o processo de rascunhos (sketchs), no qual diversas ideias apareceram e foram discutidas por todos os envolvidos no Prejeto Carnaval, levando em consideração os materiais que haviam na escola, peças já utilizadas no carnaval passado e a opinião do orientador no quesito complexidade de execução por parte da comunidade, e volume, com intuito de, no momento do desfile, unificá-las todas, formando um grande "tapete". De acordo com Mike Baxter (2011, p. 102), essa etapa é a mais importante para o projeto de produtos pois "a finalidade de geração de ideias é produzir todas as possíveis soluções. A seleção tentará escolher a melhor delas." 
Com o término dessa etapa, começou-se a produção de protótipos e moldes que seriam utilizados pela comunidade da Coroa Imperial para sua produção em série. Talvez esse tenha sido o maior desafio para os integrantes do Labsol, pois a maioria de seus integrantes jamais lidaram com a produção de fantasias carnavalescas. Mas mesmo depois de dificuldades como essa e de contratempos como o afastamento médico do orientador, o Labsol conseguiu completar todos seus modelos a tempo. Possibilitando a comunidade, em teoria, produzi-las em tempo hábil.

Nas etapas seguintes do desenvolvimento desse artigo será descrito como cada ala foi idealizada e a que porção do enredo (tema da ala) procura representar. Além de detalhes da técnica utilizada para a confecção das fantasias e materiais pensados pelos integrantes do Labsol nas etapas aqui relatadas. Nesse esforço, espera-se criar um relato que seja relevante do ponto de vista do Design quanto à sua contribuição cultural para a sociedade.

\subsubsection{Comissão de frente - Sol e Lua}

Símbolos e entidades presentes nas ricas religiões e cosmogonias dos povos do período pré-colombiano, as referências para a construção das fantasias foram trajes astecas para a forma da capa e do cinturão, as representações do calendário Maia que conforma a pala e a cabeça, e da face da deusa da lua presente no acabamento do cinturão e na parte posterior da cabeça. A pedido da coreógrafa da Comissão de Frente, Priscila Lopes, foi usado um elemento de alegoria de mão em forma de uma lança com plumas. Para a estrutura de pala e cabeça foi usado plástico corrugado de polipropileno alveolar, mais resistente ao suor e chuva que o papelão corrugado, grande parte dos elementos de seu acabamento proveio de uma doação de material residual de uma empresa doado à Coroa. Optou-se pelo forro tinto sintético na capa e saia por seu baixo custo, porém com cores vibrantes e muito leve.

\subsubsection{Ala 1 - Povos Pré-colombianos}

Milhares de anos antes da chegada dos europeus, nosso continente já era uma terra habitada por civilizações bastante desenvolvidas, com complexa organização social, conhecimentos matemáticos e astronômicos, arquitetura e engenharia avançadas, linguagem escrita e detentoras de técnicas de agricultura. Milhões de pessoas viviam por aqui e a magnitude de seus feitos é atestada pelos registros arqueológicos, que vão desde objetos do cotidiano, passando por pirâmides e chegando a cidades inteiras. Dentre as civilizações estabelecidas naquele tempo, podemos destacar tanto os Incas, habilidosos construtores em pedra, quanto os astecas, que dominavam grande parte da mesomérica e são famosos pelas belas construções piramidais.

A fantasia foi construída da reinterpretação de roupas astecas e Maias, usando componentes de fantasias de desfiles anteriores, uma cabeça com plumas roxas e escamas vermelhas de 2015, a pala com escamas vermelhas e roxas de 2014 e um cinturão com formato fractal da ala da folia de reis em 2015. Originalmente, o poncho dessa fantasia era composta por um tecido de tolha natalina na frente e no verso, mas por um problema de abastecimento do material, optamos por tirar a parte traseira a fim de reduzir o problema do projeto, acrescentando um tecido roxo proveniente de doação em seu lugar. 
"As técnicas de redução do problema examinam os componentes, características e funções do problema, tentando resolvê-lo, modificando uma ou mais dessas características. Elas se propõem a resolver o problema, mudando apenas alguns aspectos desse problema." (BAXTER; 2011, p. 99)
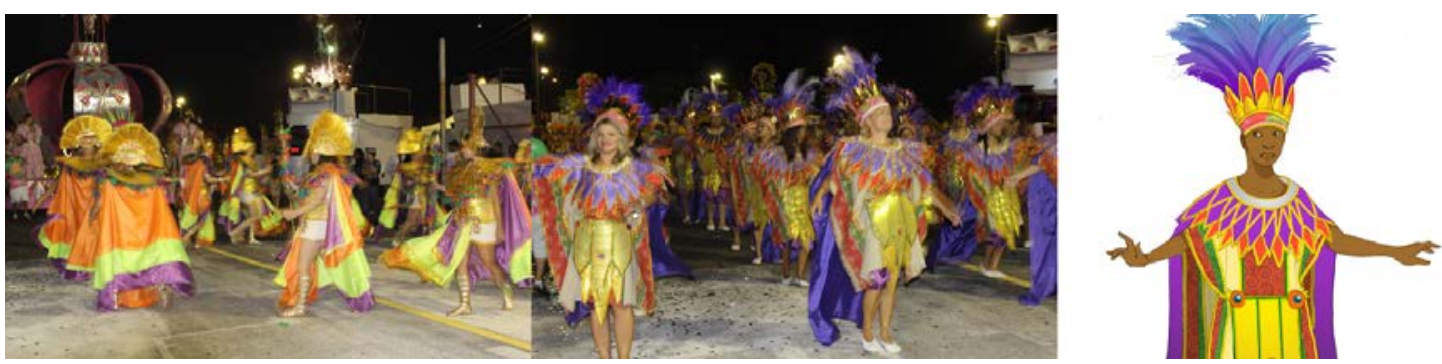

Figura 1 - Comissão de Frente - Sol e Lua.

Figura 2 - Povos Pré Colombianos.

Figura 3 - Ilustração Fantasia Povos Pré Colombianos.

Fontes: Figuras 1 e 2 - Elaborado pelo Labsol com base na pesquisa realizada.

Figura 3: Artbook Coroa Imperial 2016.

\subsubsection{Mestre-sala e Porta-bandeiras - Deuses pré-colombianos do Sol e da Lua}

Essas fantasias costumam ser as mais importantes do cortejo carnavalesco, o casal é responsável sozinho por um dos quesitos de avaliação do desfile. Além de luxuosas, estas fantasias devem possibilitar uma grande desenvoltura de movimentos coreográficos tradicionais no bailado do casal. A pedido da porta-bandeira, que desejava uma fantasia de cor preta, optou-se por representar a deusa da Lua e da Serpente, Ixchel, na mitologia Maia e o mestre-sala o deus sol Kukulcán em dourado. As fantasias foram recobertas por ricos bordados representando a cultura Maia.

\subsubsection{Ala 2 - A Costa Atlântica. Tupis}

De acordo com Darcy Ribeiro (1995, p. 31) "Os grupos indígenas encontrados no litoral pelo Português eram principalmente tribos de tronco tupi que, havendo se instalado uns séculos antes, ainda estavam desalojando antigos ocupantes oriundos de outras matrizes culturais.". Aos tupis devemos muita da nossa culinária, nossa música, folclore, do nosso jeito de falar e de muitas palavras e nomes que usamos no dia a dia: pipoca, tapioca, jacaré e, especialmente, Bauru, nome da cidade em que se realizou o desfile.

A fantasia inspira-se livremente no artesanato tupi, o cocar e a pala foram reaproveitados da ala do Carimbó de 2015 acrescidas de penas de pato tingidas de laranja, e penas artificiais de araras. Para o corpo da fantasia usou-se tecido de algodão cru com aplicações de chita escura remetendo ao artesanato tupinambá.

\subsubsection{Ala 3 - Europeus. Portugueses e espanhóis}

Em busca de novas rotas para chegar às Índias a procura de especiarias, os portugueses decidiram navegar sentido oeste e chegaram em 1500 numa nova terra que chamaram Brasil. Em várias expedições com suas caravelas, os ibéricos exploraram essa terra, consumindo grande extensão das florestas de pau-brasil. Durante essa exploração, os portugueses trouxeram sua cultura, influenciando os nativos, 
catequizando-os e forçando-os ao trabalho escravo, escravizando também os negros trazidos da África em navios, além de roubar seus nomes e demonizar sua religião.

Para a construção desta fantasia usou-se o corpo vermelho da ala dos caboclinhos, tecidos e rendas da ala da quadrilha e uma estrutura de costeiro, já usada na Escola, com soldadas de barras leves de ferro que permitiram a representação de velas das naus ibéricas com um efeito extraordinário no desfile. Essa ala recebeu 0 troféu "Tamborim de Ouro" como a melhor ala do carnaval de 2016 em Bauru.

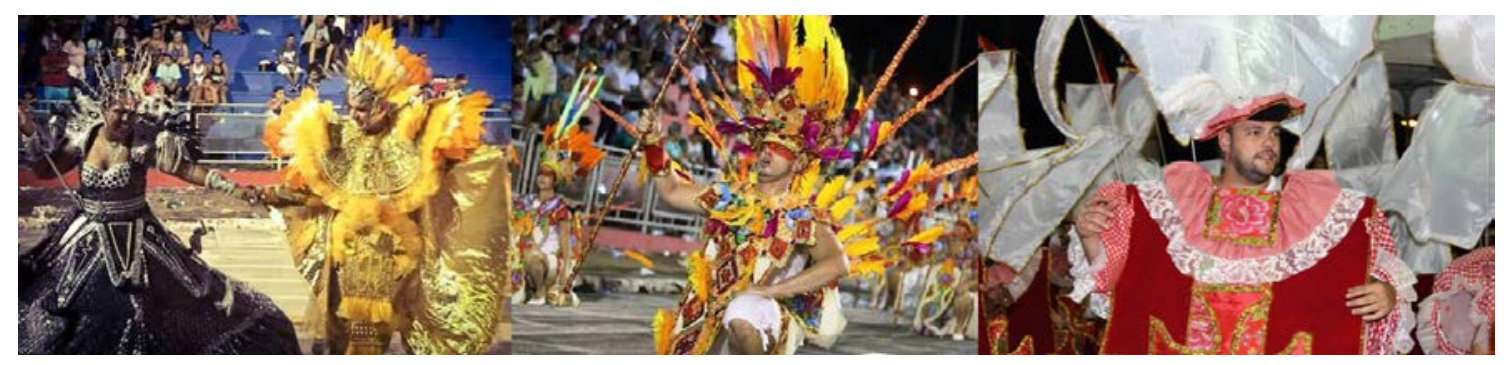

Figura 4 - Mestre-sala e Porta-bandeiras - Deuses pré-colombianos do Sol e da Lua.

Figura 5 - A Costa Atlântica. Tupis.

Figura 6 - Europeus. Portugueses e espanhóis.

Fontes: Figuras 4 e 5 - Disponíveis em facebook.com/carnavalembauru.

Figura 6: Elaborado pelo Labsol, com base na pesquisa realizada

\subsubsection{Ala 4 - Caribe}

Região formada pelo Mar do Caribe e seu conjunto de ilhas. O nome Caribe significa valente, audaz. Essa região é famosa pelas praias paradisíacas, clima tropical e pela sua população, que parece ser inspirada pela paisagem e clima para ter uma cultura rica em festivais, músicas, comidas e folclore. O Caribe é um grande caldeirão de misturas e miscigenação de povos, etnias, línguas, cores, sabores. A fantasia desta ala reflete a essência caribenha, com cores quentes e vivas e babados com estampas alegres para fazer alusão à exuberância da região, assim como às festas e danças das diferentes culturas presentes no Caribe e a produção de açúcar que por muitos anos foi o principal produto da região.

Nesta ala foram usados babados coloridos de diversas alas do desfile de 2015, a pala e cabeça surgem do recorte do corpo da ala da folia de reis, para a representação da cana usou-se capim holográfico usado em 2014 e os elementos que representavam cactos na ala do forró de 2015.

\subsubsection{Ala 5 - Andes / Incas}

As civilizações andinas compunham um mosaico de diferentes culturas independentes que se desenvolveram no entorno da Cordilheira dos Andes, da Colômbia ao deserto de Atacama. O Império Inca foi a última entidade política soberana que emergiu das civilizações andinas antes da conquista espanhola.

Um importante símbolo para a cultura dos povos andinos são os metais preciosos e a mineração. Com isso, foi criado uma fantasia formada por poncho, bermuda e cabeça.

O poncho era feito com tecido rosa, abundante na escola, com pedraria verde, que além de remeter as cores da Coroa, é uma paleta frequentemente utilizada pelos 
povos andinos. A bermuda branca era composta por bordados rosa, verde e dourado e a cabeça era de formato semicircular de papelão corrugado dublado em tecido dourado, com detalhes e bordados em rosa, dourado e verde, além de aplicação de
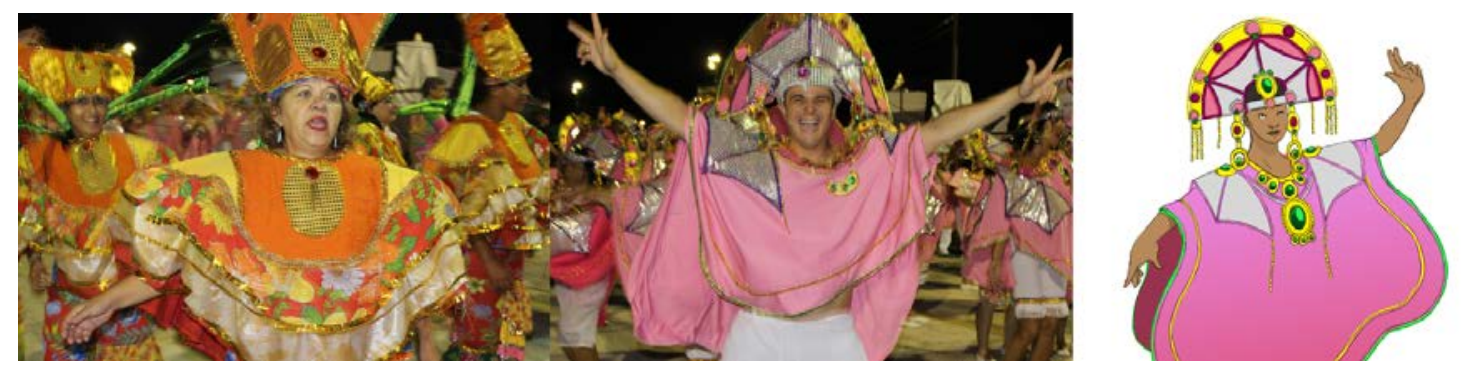

pedraria rosa.

Figura 7-Caribe.

Figura 8 - Andes/Incas.

Figura 9 - Ilustração Fantasia Andes / Incas.

Fontes: Figuras 7 e 8 - Elaborado pelo Labsol, com base na pesquisa realizada.

Figura 9 - Artbook Coroa Imperial 2016.

\subsubsection{Bateria - Africanos}

As culturas africanas tiveram grande influência na formação cultural latinoamericana, notadamente nos países do Atlântico. Muitos são os aspectos culturais que sofreram influência africana, nos ritmos musicais, culinária e na religião.

A fantasia procura representar um guerreiro africano, formada por uma bata de tecido com estampa de animal, uma cabeça e um cinturão originalmente proposto que foi retirado para permitir maior liberdade de movimentos e não interferir no uso de instrumentos de percussão mais pesado como os surdos, caixas e repiliques. Vale destacar também o colar circular preenchido com resíduos de e.v.a doados por uma indústria local.

\subsubsection{Baianas - Oxalá}

A roupa, completamente branca, é referência a versão mais velha e sábia do orixá e seu completo repúdio a violência. O turbante é inspirado nas mulheres do candomblé que lavam as escadarias da Igreja de Nosso Senhor do Bonfim, na Bahia, ao som de toques e cânticos sagrados.

Optou-se por uma fantasia muito leve, relendo as roupas tradicionais das baianas, permitindo uma evolução muito grande por parte de suas integrantes, o uso do branco puro, sem elementos de decoração, além de diminuir o custo da fantasia criou um grande impacto no desfile, foi usado um tecido de baixo custo, forro tinto sintético entremeado por cetim liso e adamascado brancos. 

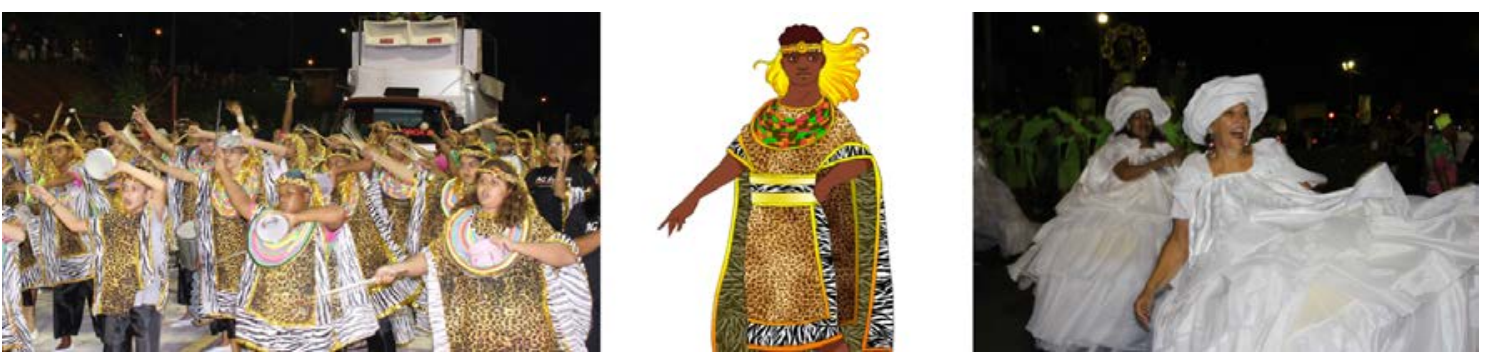

Figura 10 - Bateria - Africanos.

Figura 11 - Bateria - Africanos.

Figura 12 - Baianas - Oxalá

Fontes: Figuras 10 e 12 - Elaborado pelo Labsol, com base na pesquisa realizada.

Figura 11 - Artbook Coroa Imperial 2016.

\subsubsection{Ala 6 - Patagônia. Pinguins}

Ao extremo sul do continente se encontra a Patagônia, região que abrange a parte mais meridional da América do Sul, o sul das Cordilheiras dos Andes localizada na Argentina e Chile. Região de belas paisagens naturais é o habitat de golfinhos, baleias, leões-marinhos e uma grande concentração de pinguins. Essas pequenas aves abundantes na região são da espécie Pinguins-de-Magalhães.

Essa fantasia visa representar os pinguins de magalhães de modo cômico, fazendo uma analogia de suas características corporais com um fraque. O tecido preto usado na fantasia provém de resíduos da indústria automotiva, adquiridos com baixo custo em uma loja da cidade de Bauru, entretanto esta fantasia foi levada ao desfile sem que fosse colocada sua estrutura, devido a um erro técnico por parte da comunidade que não entendeu o real motivo de sua utilização, o que prejudicou a performance desta peça na avenida.

\subsubsection{Ala 7 - Chaco}

Uma das áreas centrais do continente sul-americano e alagada pelos rios da Tríplice Aliança é o Chaco, conhecida no Brasil como Pantanal. Reserva incontestável da fauna latino-americana, com incríveis belezas naturais. Para representar o Chaco, que ocupa porções do Brasil, Bolívia e Paraguai, utilizamos o principal representante da sua fauna, o jacaré. Um toque cômico é dado pelos óculos "rústicos", importados do Paraguai. A fantasia é confeccionada em papelão por nossa preocupação com a sustentabilidade, revestida de tecido verde limão. Para os olhos foram utilizadas bolinhas de natal, recicladas da fantasia dos guarda-chuvas do carnaval de 2014.

\subsubsection{Ala 8- Pampas}

O pampa é um bioma característico de planícies, localizados na região Sul do Brasil com Uruguai e Argentina. A fantasia traz referências aos trajes gaúchos e as bandeiras destes países. Esta também é uma região de grandes times de futebol representados aqui por bolas de futebol coladas sobre chapéus de origem espanhola. 


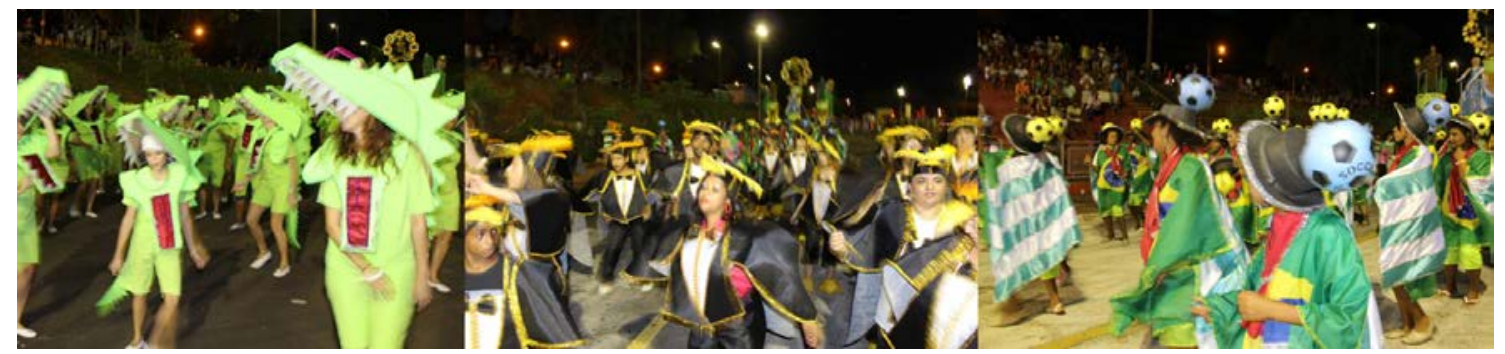

Figura 13 - Chaco.

Figura 14 - Povos Pré Colombianos.

Figura 15 - Pampas.

Fonte: Elaborado pelo Labsol com base na pesquisa realizada.

\section{CONCLUSÃO}

Ao final do desfile da Coroa Imperial, pode-se perceber que o trabalho do Labsol, mesmo com seus infortúnios e dificuldades teve seu objetivo completo. As fantasias foram feitas com os materiais possíveis, levando em conta todo o histórico da escola e suas habilidades. Mesmo que no momento do desfile algumas das alas tenham sido prejudicadas seja pelos próprios integrantes, ou pelos dirigentes, concluímos nosso objetivo e ainda fomos prestigiados por um "Tamborim de Ouro" pela ala dos "Europeus. Portugueses e Espanhóis".

Percebemos no final do Carnaval 2016 que a postura da escola em relação aos materiais foi diferente, a maioria dos materiais fora reservado para que no ano seguinte eles possam utilizá-los de novo e assim reduzam o impacto de suas fantasias, além dos custos dessas. Com isso podemos ver como a ação do Labsol teve resultados palpáveis, pois além da postura da comunidade, muitos dos integrantes tiveram a experiência do design aplicado a realidade. Tiveram a percepção de que nem todos os conceitos são realmente acessíveis, principalmente aqueles que fazem parte das grandes massas, pessoas essas que sempre devem ser focos do Design. Um design real, acessível e social.

\section{REFERÊNCIAS}

BAXTER, Mike. Projeto de Produto, Guia prático para o design de novos produtos. Tradução Itiro lida. Editora Blucher, 2011.

BORGES, Adélia. Design+Artesanato. São Paulo: Terceiro Nome, 2011

BREZET, H. VAN HEMEL, C. BÖTTCHER, H. CLARKE, R. Ecodesign: a promising approach to sustainable production and consumption: UNEP, 1997.

FREIRE, Paulo. Pedagogia do oprimido. 17ạ edição, Paz e Terra, Rio de Janeiro, 1987.

GOYA, C. R.; ANDRADE, A. B. P.; DOMICIANO, C. L. C.; ROSSI, D. C.; MEDOLA; F. O.; HENRIQUES, F, SILVA, J. P. C., PASCHOARELLI, L. C.; MOURA, M.; RODRIGUES, O. V.; BIGAL, S. M.; BARATA, T. Carnaval, Cultura Popular e Design - Uma Experiência de Extensão Universitária em Design In: Ensaios em Design - Práticas Interdisciplinares.1 ed. Bauru: Canal 6 Editora, 2014, p. 136-156. 
MANZINI, Ezio; VEZZOLI, Carlo, trad. CARVALHO, Astrid de. O Desenvolvimento de Produtos Sustentáveis: os requisitos ambientais dos produtos industriais. São Paulo: EDUSP, 2002.

RIBEIRO, Darcy. O Povo Brasileiro - A Formação e o Sentido do Brasil. São Paulo: Companhia das Letras, 1995.

SINGER, Paul. Introdução à Economia Solidária. São Paulo: Fundação Perseu Abramo, 2002. 